\title{
"Somos sobreviventes": vivências de servidores públicos de uma instituição de seguridade social diante dos novos modos de gestão e a precarização do trabalho na reforma gerencial do serviço público
}

\author{
Elisete Soares Traesel \\ Centro Universitário Franciscano (Santa Maria, RS) \\ Álvaro Roberto Crespo Merlo \\ Universidade Federal do Rio Grande do Sul (Porto Alegre, RS)
}

\begin{abstract}
O objetivo desta investigação foi conhecer a realidade de um órgão público no contexto da atual reforma gerencial. Atentou-se para as vivências e condições de trabalho dos trabalhadores, bem como as repercussões destas em sua saúde mental. O método utilizado foi a PDT-Psicodinâmica do Trabalho, que propõe a escuta coletiva dos trabalhadores. Verificou-se a precarização do contexto de trabalho, em especial, no sofrimento relativo às metas extenuantes, falta de reconhecimento da função social e importância do servidor público, associadas ao desmoronamento do sentido do ofício, que deveria ser voltado ao bem comum, diante da prevalência da lógica de mercado na aplicação dos novos modos de gestão que desconsideram os resultados sociais. Ainda verificou-se insegurança evidenciada pela descontinuidade da renda e falta de oportunidades de qualificação e crescimento, além da intensa sobrecarga de trabalho. O orgulho pela profissão, o prazer por garantir os direitos do cidadão e o reconhecimento e valorização desse importante papel social, assim como a retomada dos coletivos de trabalho por meio da criação de espaços públicos de discussão, conforme propostos pela PDT, podem constituir estratégias de enfrentamento na promoção de relações de trabalho mais saudáveis e emancipatórias.
\end{abstract}

Palavras-chave: Servidor público, Reforma gerencial, Psicodinâmica do Trabalho.

\begin{abstract}
"We are survivors": experiences of being a public servant at INSS considering the new management modes and precarious work conditions in public service management reform

This research aimed to understand the reality of a Brazilian public corporation in the context of current management reform, the workers' experiences and working conditions, as well as its impacts on their mental health. The methodology used was PDT (in Portuguese) - Psychodynamics of Work, which proposes collective listening workers' experiences. It was possible to verify precariousness in the work context, revealed in particular from suffering in achieving goals and lacking of recognition to the importance of being public servants in what regards the social outcomes of their work, associated to the collapse of common ethics that maintain working sense. Besides, there was (in)stability demonstrated from discontinuity of salary, lack of growth opportunities and also from intense workload. The pride, in this profession, the pleasure in ensuring people's rights and the recognition and appreciation of its important social role, as well as the resumption of work collectives by means of discussion spaces, as proposed by PDT, may create facing strategies to promote healthier working relationships and emancipatory actions.
\end{abstract}

Keywords: Public service, Management reform, Psychodynamics of Work.

\section{Introdução}

$\mathrm{P}$ or meio da presente pesquisa pretendeu-se conhecer mais profundamente as vivências dos trabalhadores públicos na atualidade, em especial no que se refere aos servidores de uma gerência regional de uma instituição de seguridade social, diante da reforma gerencial que adentrou este setor priorizando os resultados econômicos em detrimento dos resultados sociais.

Segundo Gaulejac (2007), a sociedade contemporânea caracteriza-se como gerencial, regida pelo universo econômico. Este ideário gerencial penetra todos os segmentos, inclusive o setor público, desconsiderando sua cultura e valores. Tais princípios gerencialistas norteiam a reforma gerencial da administração pública na atualidade, fundamentada em resultados em detrimento 
dos princípios éticos do serviço público, com profundos impactos sobre a saúde e subjetividade do servidor (Chanlat, 2002; Supiot, 1995).

Para Seligmann-Silva (2011), um dos aspectos mais dolorosos dos novos modos de gestão está na flexibilidade e desregulamentação dos contratos de trabalho, que estão no cerne de todos os processos de reestruturação produtiva. Tais modos ainda criam uma dinâmica precarizadora também no serviço público, a qual pode ser observada nas terceirizações que acarretam degradação ética e moral capaz de gerar sobrecarga e pressão além dos limites, configurando um profundo desgaste mental.

O contexto da investigação é uma gerência regional de um órgão público vinculado à previdência social brasileira, onde predomina o exercício de uma função social cujo foco está na garantia de direitos. A escolha do local deu-se devido a um contato efetuado pela equipe de saúde desta organização. Solicitou-se o desenvolvimento de uma pesquisa com enfoque na saúde mental dos servidores tendo em vista que, em um levantamento prévio efetuado pelos profissionais da equipe, ficou evidenciado que os trabalhadores estavam apresentando abalos em sua saúde mental relacionados ao trabalho.

Salienta-se que, apesar de ser um ambiente de trabalho desejado por muitos, o que se constata pela relação candidato/vaga dos concursos, e em função da suposta estabilidade no emprego, é que o serviço público tem sido lócus de conflitos e vivências de sofrimento relacionados a práticas perversas de gestão, competição, falta de reconhecimento, invisibilidade e assédio moral.

Nesse sentido, Carneiro (2006) aponta que pesquisas têm revelado a exposição dos trabalhadores do serviço público a sofrimento advindo das condições de trabalho, mas, principalmente, com origem na forma pela qual o trabalho organiza-se. Da mesma maneira, a administração pública ainda não se apropriou adequadamente desta questão e, portanto, não consegue responder às demandas do servidor público, sendo, ainda, a perícia médica, por obrigação legal, a principal ou talvez a única ação realizada a fim de controlar a ausência ao trabalho.

Ainda existem poucos trabalhos e estudos que abordam essa realidade, bem como há limitadas experiências no campo da prevenção e promoção de saúde do servidor público que ajudem na orientação à construção de políticas públicas voltadas a ela (Carneiro, 2006; Carneiro, 2011; Ferreira, Alves \& Tostes, 2009). Todavia, houve um importante avanço a partir da construção do documento "Princípios, Diretrizes e Ações em Saúde Mental no âmbito da Administração Pública Federal", que ainda está em fase de implantação no serviço público (Brasil, 2010).

Conforme Carneiro (2011), o trabalho público apresenta traços e proporciona a vivência de situações que tendem a influenciar a saúde do servidor e portanto devem ser consideradas nas ações de prevenção e promoção de saúde. São, por exemplo, a multiplicidade de riscos inerentes aos diversos cargos e funções; as tensões existentes entre exigências burocráticas e demandas políticas; a interferência dos órgãos de comunicação de massa; os diferentes estratos sociais que adentram por concurso; a instabilidade relacionada a mudanças políticas, por vezes antagônicas; a pressão por produtividade e eficiência referenciada em balizadores do setor privado; o conflito entre os poderes burocrático, técnico e político e, ainda, a imagem depreciativa do servidor público perante a sociedade.

Além disso, faz-se muito importante salientar que os programas de gestão de pessoas e qualidade de vida no trabalho que têm sido implantados nos órgãos públicos estão, frequentemente, descontextualizados da realidade e das necessidades de seus servidores. A reforma gerencial tem apenas transferido tecnologias de gestão do setor privado para o setor público, sem considerar as peculiaridades do trabalho e do trabalhador. Nesta perspectiva, essas mudanças não levam à modernização importante e necessária no processo de gestão desse setor, e sim transformamse em uma ameaça à saúde e ao bem estar do servidor, pois o nível e característica da pressão por desempenho desconsideram a lógica própria do serviço público com profundo impacto na subjetividade e nas relações de trabalho (Ferreira et al., 2011; Siqueira e Mendes, 2009;). 
Dessa forma, o presente artigo apresenta os resultados parciais de uma tese de doutorado que teve como objetivo geral conhecer, na perspectiva da PDT - Psicodinâmica do Trabalho, as vivências dos servidores públicos de uma instituição em que predomina o exercício da função social em contexto de reforma gerencial, assim como suas repercussões sobre a saúde e qualidade de vida do servidor.

\section{Panorama e Repercussões da Reforma Gerencial no Serviço Público}

Paes de Paula (2012) faz uma análise dos modos de gestão atuais do setor público e considera que a reforma gerencial levou à fragmentação do aparelho de Estado, tendo em vista que os modos atuais não substituem os antigos; verificou-se, na realidade, a convivência de ambos e a perda de referências. O que se constata é a existência de uma flexibilização da burocracia aliada à manutenção da dominação.

Além disso, a administração pública gerencial continua reproduzindo a centralização do poder, o autoritarismo e o patrimonialismo. O processo decisório permanece no núcleo estratégico do Estado e de instâncias executivas, sendo que o ideal tecnocrático foi reconstruído pela nova política de recursos humanos. O novo modelo, ainda, não garante a participação da sociedade civil nas decisões estratégicas e no planejamento das políticas públicas.

Tal reforma teve como princípios norteadores a revisão do papel do Estado no que se refere, em especial, a sua capacidade de intervenção no desenvolvimento econômico e social; teve também uma nova definição de métodos, técnicas e instrumentos de gestão administrativa, criticando a administração burocrática e reproduzindo estratégias advindas da administração de empresas. Em consequência, a reforma levou à proposição de uma administração pública gerencial, cujo foco encontra-se no controle de resultados e na primazia pela eficiência e efetividade dos serviços prestados, bem como na flexibilização dos modos de contratação e remuneração dos servidores.

Conforme Vaistman (2001), esses conceitos desenvolvidos inicialmente pela e para a realidade norteamericana, principalmente por Osborne e Gaebler em 1994, surgem do pressuposto de que os servidores públicos têm alguns traços específicos relativos à gestão; ou seja, competência para a autogestão, autonomia, iniciativa e compromisso com o serviço público. Assim, defendem que a avaliação de desempenho deve ocorrer por meio dos resultados alcançados. Contudo, tais práticas desconsideram características próprias da realidade brasileira.

Brulon, Ohayon e Rosenberg (2012) apresentam o panorama e o cenário da reforma gerencial no Brasil. De acordo com os autores, diante das contundentes críticas ao modelo burocrático de administração que era vigente no país até o final do século XX, passa a acontecer uma proliferação de reformas gerenciais, alavancadas principalmente pelo movimento de Administração Pública Gerencial, ou Nova Gestão Pública (New Public Management). Tal movimento baseava-se essencialmente em resultados e práticas inovadoras voltadas para o aumento do desempenho, impactando a gestão pública de vários países.

Secchi (2009) acrescenta que desde a década de 80 houve mudanças significativas nas administrações públicas em todo o mundo. Tais reformas colocam em ação novos discursos e práticas advindas do setor privado, utilizando-as como casos de sucesso para as instituições públicas em todas as instâncias governamentais. Trata-se da aplicação de um modelo normativo pósburocrático para estruturar a gestão da administração pública que se fundamenta nos princípios de eficiência, eficácia e competitividade. Na visão do autor, nesses modelos pós-burocráticos há a preocupação com a ascensão dos princípios neoliberais e com a função controle, tornando permeáveis as esferas públicas e privadas e transformando o cidadão de usuário em cliente. 
Dessa forma, constata-se que, em nosso país, mesmo que a reforma gerencial não tenha sido concluída, o modo gerencial de administrar tem protagonismo na administração pública moderna, havendo uma tendência muito forte de inserir reformas administrativas norteadas pelo mesmo modelo. Ainda, mesmo que os esforços de reforma gerencial culminem mais em apelos políticos de promoção de imagem e conquista de votos, não deixam de ter um efeito devastador sobre todos os envolvidos no processo, particularmente sobre os trabalhadores que são convocados a colocar em prática o que foi planejado sem sua participação.

Segundo Brulon, Ohayon e Rosemberg (2012), a aplicação da lógica financeira do mercado e dos princípios neoliberais invade a gestão pública, notadamente, a partir das reformas que aconteceram em países como Reino Unido, Estados Unidos, Nova Zelândia e Austrália. Passa, então, a ser aplicada em vários países do mundo sem maiores adaptações ou reflexões sobre seus impactos, inclusive no Brasil, em um contexto de crise do Estado. Analisando sua implantação na América Latina, constata-se que os países que mais avançaram no processo foram o Brasil e o Chile, sendo que nos demais as tentativas foram frustradas.

Voltando ao caso brasileiro, os autores asseveram que, tal como outros países do mundo, o Brasil passou por um período considerado de crise do Estado burocrático que gerou a sensação de ser necessário efetuar uma reforma ou reconstrução em suas práticas. Contudo, o país considerou-se legalmente preparado para iniciar a administração gerencial apenas em 1995.

Segundo Pinto (2009), no Brasil, a primeira fase da reforma gerencialista aconteceu já no governo de Collor de Mello e permaneceu nos dois mandatos de Fernando Henrique Cardoso (FHC). A pauta da reforma tinha como tópicos principais o ajuste fiscal; as reformas econômicas voltadas para o mercado, enfatizando a privatização das estatais; reforma da previdência social e, por fim, reforma do Estado, visando ao incremento da capacidade de governo.

A autora acrescenta que ao criar o MARE (Ministério da Administração e Reforma) em 1995, Bresser-Pereira estava em sintonia com o pensamento internacional sobre administração pública e fortemente aliado a FHC, que lhe conferiu toda a autonomia para definir sua equipe ministerial e planejar a reforma gerencial.

Bresser-Pereira (2009) caracteriza e denomina a reforma por ele planejada como reforma gerencial, visto que foi inspirada na gestão de empresas privadas com o intuito principal de construir uma administração pública mais eficaz, considerando que a mesma lança os pilares para um regime democrático. Defende, também, que é uma reforma social-democrática e social-liberal devido à existência de um Estado que garante os direitos sociais e reconhece o mercado como um excelente alocador de recursos.

Na perspectiva do idealizador da reforma, esta inclui três dimensões: institucional, que se refere à criação de instituições que a viabilizem; cultural, que implica mudança de valores burocráticos para gerenciais; e, por fim, a dimensão gestão, que diz respeito à aplicação dos novos princípios gerenciais.

Brulon, Ohayon e Rosenberg (2012, p. 273) apontam alterações importantes na gestão de pessoas desde que Bresser-Pereira apresentou a emenda constitucional. Os autores destacam: "a previsão de mecanismos de flexibilização da estabilidade, a exigência de avaliação para alcançar a estabilidade ao fim do estágio probatório, a proibição de aumentos em cascata e o reforço do teto e subteto de remuneração dos servidores". O então ministro justificou que tais mudanças tinham o intuito de reduzir custos, melhorando a eficiência e a qualidade do serviço público. A prerrogativa era, assim, flexibilizar o sistema de estabilidade e, ainda, desfazer o Regime Jurídico Único de contratação (Bresser-Pereira, 2009). Agrega-se a isso a implantação de programas de qualidade que visavam à melhoria contínua da performance institucional, com a meta de ampliar o grau de satisfação dos usuários tendo como instrumento métodos de avaliação da gestão pública. 
Conforme os autores, no Brasil a administração pública evoluiu por meio de três modelos básicos: administração patrimonialista, burocrática e gerencial. As três se sucederam no tempo, mas nenhuma foi totalmente abandonada. Assim, pode-se considerar que traços de modelos anteriores permanecem vivos no modelo atual, acirrando as contradições organizacionais.

Ao encontro do acima exposto, Secchi (2009) considera que os novos modelos de gestão pública guardam características do tradicional burocrático e, dessa forma, não podem ser vistos como modelos de ruptura. Complementando a ideia, o autor argumenta que "até mesmo o patrimonialismo pré-burocrático ainda sobrevive por meio de evidências de nepotismo, gerontocracia, corrupção e nos sistemas de designação de cargos públicos baseados na lealdade política" (Secchi, 2009, p. 365).

Em concordância, Paes de Paula (2005) pondera que, no contexto da nova administração pública, a visão de profissionalização e formação de competências no serviço público ganhou traços gerencialistas, sob o argumento de substituir a burocracia. Contudo, essa burocracia, altamente criticada, visava a assegurar a todos os cidadãos igualdade de direitos e, ao servidor, imparcialidade e neutralidade no exercício de seu fazer em prol do público. Na lógica gerencial, porém, a burocracia não acabou, apenas foi substituída por uma burocracia flexível e instável, que inviabiliza a democracia e cujas características seguem a ordem contemporânea de flexibilização organizacional. Além disso, Secchi (2009) acrescenta que as reformas feitas em nossa administração pública rapidamente tornam-se políticas simbólicas, no intuito de manipular a percepção das pessoas em relação à performance dos políticos, constituindo-se mais em autopromoção e discurso do que em ações concretas.

Nesta direção, Brulon, Ohayon e Rosenberg (2012) analisam a reforma gerencial brasileira e constatam que a mesma tem sido foco de um discurso muito positivo que a coloca como instrumento de modernização e eficiência na administração pública, sendo difícil contrapor estes argumentos sem que se passe a impressão de que se está indo contra o avanço e desenvolvimento do País. Consideram que o modelo até pode ter trazido alguns benefícios, tais como a busca por um melhor atendimento ao usuário, redução de gastos públicos e, ainda, a criação de agências reguladoras. No entanto, estes foram implementados sem orientação para a sociedade e com descumprimento do papel social, o qual passou a figurar como secundário.

Em suma, pode-se constatar, a partir desse breve histórico, que a eficiência econômica tornou-se um fim sendo que deveria ser apenas um meio. Sendo assim, é impossível deixar de perceber as vulnerabilidades de sua implementação, principalmente devido ao fato de desconsiderar completamente a cultura, especificidades do serviço público e necessidades do servidor.

\section{Delineamento da pesquisa}

Os resultados apresentados neste artigo são oriundos de uma etapa da pesquisa com os servidores públicos mencionados acima, em que foi aplicada a metodologia da PDT - Psicodinâmica do Trabalho. Tal método consiste em escuta coletiva das vivências dos trabalhadores e construção de um espaço de discussão que possibilite a circulação da palavra. Seu enfoque é qualitativo e visa propiciar um aprofundamento na compreensão da realidade vivenciada e à ação e intervenção sobre o trabalho, com vistas à construção de estratégias coletivas de emancipação. Situa-se, assim, na ótica da pesquisa-ação, conforme preconiza Dejours, 2011.

Segundo Merlo e Mendes (2009), a teoria e o método em Psicodinâmica do Trabalho em suas aplicações atuais seguem os pressupostos de Christophe Dejours, que considera que pesquisa e ação são indissociáveis. Faz-se importante salientar que a presente investigação está fundamentada tanto a nível teórico quanto metodológico nesses pressupostos. 
No que se refere à coleta de dados, foram construídos grupos para escuta coletiva dos trabalhadores em exercício, envolvendo todos os setores da instituição. Dessa forma, participaram do estudo 51 trabalhadores de uma gerência regional da instituição pesquisada, os quais concordaram voluntariamente em fazer parte da pesquisa.

Ressalta-se que a escuta coletiva e a análise e interpretação dos resultados seguiu os fundamentos da metodologia da PDT, sendo que serão apresentados em relatório comentado constituído por eixos temáticos, construídos em etapa posterior à análise dos resultados. Neste artigo, será apresentado um destes eixos temáticos que aborda as vivências dos servidores diante da reforma gerencial do serviço público e da precarização das relações de trabalho neste contexto. Esta análise baseou-se na observação clínica e na interpretação da intersubjetividade que se construiu no espaço de discussão entre os participantes e pesquisadores, buscando dar voz aos participantes por meio da circulação da palavra impulsionada pela escuta coletiva (Dejours, 1992, 2011).

Assim, foram reunidos grupos de servidores dos diferentes setores que aceitaram o convite à participação, o que oportunizou espaço de escuta coletiva para todos. Cada grupo teve entre 4 e 8 participantes. Todos os setores participaram, sendo realizado pelo menos um encontro com cada grupo de servidores e, ao todo, 12 encontros.

Quanto aos procedimentos éticos, o projeto da presente pesquisa foi aprovado pelo Comitê de Ética do Instituto de Psicologia Social e Institucional da UFRGS sob no 89.792, conforme parecer consubstanciado do CEP favorável à realização do estudo. Foram seguidos todos os preceitos éticos da pesquisa com seres humanos preconizados pela legislação brasileira, tendo como fundamento a Resolução 4.66/2012 do Conselho Nacional de Saúde (Brasil, 2012).

\section{Apresentação dos resultados}

\section{"Somos sobreviventes": vivências de ser servidor público diante dos novos modos de gestão e a precarização do trabalho na reforma gerencial do serviço público}

Segundo Siqueira e Mendes (2009), a modernização do Estado é fundamental a fim de tornar as estruturas mais leves e horizontalizadas, o que faz necessária a reforma. Contudo, esta não deve ser simplesmente importada do setor privado para o público, pois as singularidades deste devem ser consideradas e respeitadas. Os autores alertam, ainda, que é vital a avaliação das repercussões dessas novas formas de gestão na subjetividade do servidor, refletindo sobre os danos que a pressão desenfreada desses novos modelos pode gerar sobre a saúde e relações de trabalho.

Segundo os autores, o discurso e a prática gerencialista contemporâneos estão se reproduzindo no setor público sem uma avaliação criteriosa da ideologia que atravessa os modos de gestão das organizações privadas. Em outras palavras, a orientação gerencialista está focada nas tarefas e não nas pessoas, o que leva à precarização do trabalho e à desmotivação do servidor.

Os relatos dos servidores participantes da pesquisa ratificam a análise dos autores: "não há treinamento, há excesso de trabalho". Um colega também expõe sua opinião com a seguinte afirmação: "em 2003, saíram 70\% dos servidores. Ou fizeram outro concurso ou mudaram de profissão. Hoje ainda permanecem se não tem algo melhor, mas estão sempre atentos a outros concursos".

Outro servidor desabafa: "queríamos ter uma carreira, ter respeito. Parece que os gestores nos veem como inimigos, como problema e também nosso sindicato não é representativo da categoria". Um colega complementa: "é muito retrabalho. Faz uma revisão e depois repete tudo 
de novo". Sobre as atividades administrativas, há uma queixa de que não há incentivo apesar de muitas responsabilidades, conforme observa-se na passagem

o trabalho de chefia é pra enlouquecer, ganha uma mínima gratificação, não tem apoio, corre risco o tempo todo pela imensa responsabilidade e falta de acesso a informações precisas e ainda tem que viver cobrando, apesar de ver a sobrecarga do pessoal e a ineficácia do número expressivo de estagiários que quando aprendem, encerrou o contrato.

Outro servidor enfatiza o que os colegas do grupo estão apontando e tenta resumir a situação que estão vivendo:

pra sintetizar: é uma falta de perspectiva - a cada 18 meses, um pouquinho de aumento, sem promoção. No atendimento então, é enlouquecedor pelo excesso de atendimentos em ritmo acelerado, porque as senhas estão correndo e o tempo pra atendimento é restrito. O sistema vigia o tempo todo se está cumprindo os horários, desconsiderando as diferentes situações que são atendidas. Eu me sinto vigiada.

É frisada também, por todos os participantes, a restrição do número de servidores e a precariedade na qualificação: "tem também deficiência de pessoal, o sistema é lento e não lembro quando foi o último curso que tive". Além disso, o mesmo participante complementa o seu discurso: "a instituição não nos dá meios para dar uma boa instrução. Não há tempo ou investimento em atualização". Outra servidora relata: "nos cobram produtividade, mas não nos dão condições, incentivo, treinamento ou reconhecimento pelo nosso trabalho." E ainda: "é uma acusação constante e um clima de cobrança. Isso ofende”.

Apoiando a colega, uma servidora do grupo menciona: "é uma instituição visada e criticada. As chefias estão acuadas, têm medo de tudo". Outro acrescenta: "querem agilidade, mas não tem qualidade. É pressão do tempo e cobrança o tempo todo”. E, com um tom de voz melancólico, uma servidora com muitos anos de serviço conclui: "a instituição não faz nada por nós... nós também somos somente números, invisíveis. É como se não existíssemos".

Outro aspecto importante abordado pelos servidores públicos e que contribui para o sentimento de insegurança diz respeito à meritocracia. Eles concordam com a existência da mesma e têm ciência de sua importância, mas discordam de seus critérios argumentando que não respeitam os méritos e acreditam que predominam fortemente os interesses particulares de favoritismo e apadrinhamento político. Entendem, ainda, que as regras do jogo não são as mesmas para todos, o que leva ao não envolvimento e ao descompromisso. Os participantes apontam que, mesmo não sendo políticos, precisam fazer parte das regras do jogo: "há muita pessoalidade e pouco profissionalismo. Não entrar no jogo: isso mata!”.

Afirmam, ainda, que cada gerência pensa de uma maneira diferente, não há padrão no entendimento: se muda a gerência, modifica-se o entendimento. Isso leva à insegurança sobre o que está certo ou não: "e isso muda o tempo todo. A gente não consegue nem se adaptar". Nesse sentido, um participante ressalta o sofrimento relativo às mudanças nas chefias diretamente relacionadas às mudanças políticas: "outro estresse é a transição da troca de chefia, deram tarefa sem explicar. Isso é histórico; mudam e jogam as tarefas em cima da gente sem nenhuma explicação". Outro servidor complementa: "mas é isso que esperam de nós. Alguém promete e nós temos que cumprir, custe o que custar, sem errar, sem ser injusto, sem ter as devidas informações, com um sistema lento, com poucos servidores".

Nessa direção, um servidor desabafa, com apoio total dos colegas, demonstrando angústia e revelando, inclusive, problemas de saúde decorrentes do trabalho: "a gente que tinha vontade de trabalhar foi podado, não tenho mais vontade de fazer isso, não vale a pena tanto esforço. Acabei 
tendo que tomar medicação para pressão... não sou mais a mesma pessoa". Outro ratifica esse sofrimento vivenciado: "a administração está nos levando à loucura, aumentou a demanda e não os funcionários. Em nossa cidade, deveria ter no mínimo mais 3 postos de atendimento".

No que se refere ao favoritismo apontado, os participantes reiteram a sua existência afirmando que uns são beneficiados em detrimento de outros, como, por exemplo, no caso de os servidores serem liberados do expediente para fazerem cursos de capacitação, atualização e participarem de eventos que promovam conhecimento. Uma participante ilustra essa questão com um exemplo: "meu curso não foi aprovado. Falaram que foi prazo, mas sei que não foi. Não pude apresentar meu trabalho que tinha sido aprovado. É humilhante". Na mesma perspectiva, um colega continua: "para uns, nada pode. Outros usufruem muito. Pesa muito a questão política. Nos sentimos perseguidos, porque ninguém gosta de quem reclama. As decisões são sempre políticas". Em concordância, uma colega desabafa, demonstrando o sofrimento e também a autodefesa do mesmo, que é o isolamento e o silêncio diante da invisibilidade do zelo:

a gente sofre assédio moral quando fala, quando não concorda, quando mostra o que tem que melhorar. Daí, a gente acaba buscando um lugar seguro ou se isola, ou simplesmente cumpre a carga horária, o que a gente faz de bom não é visto mesmo.

Os participantes sinalizam, ainda, que a política muda a cada 4 anos e que tudo muda igualmente no que se refere a cargos e políticas, gerando insegurança; a gestão das pessoas, entretanto, não se altera. Apontam que não há um plano de carreira e não existem ganhos reais na remuneração fixa há vários anos, sendo que seu poder aquisitivo é sustentado por uma remuneração variável que representa mais da metade da fixa. Assim, consideram que a instituição não oferece condições para evoluírem profissionalmente: "ficamos parados no tempo, esquecidos, invisíveis. Só querem fazer política, somos palhaços, pois abrem agência e não colocam funcionários".

Outra participante aborda, também, as distorções no processo de comunicação: "nem somos informados das mudanças e novidades da previdência. Quando sai na mídia o servidor ainda não sabe. Tem muita propaganda política". Essa participante ainda exemplifica citando uma campanha veiculada pela mídia a qual prevê que o objetivo do público, ou seja, a aposentadoria, seria atendido em 30 minutos, o que, em sua opinião, não acontece na realidade. Outro participante concorda: "É só política. Dizem que estão abrindo agência, mas não colocam número adequado de servidores". Ou seja, o participante afirma que não é possível atender ao que propõe a campanha veiculada na mídia, pois não há servidores suficientes, o que acaba comprometendo a imagem desses trabalhadores, conforme esclarece: "e o bom atendimento e a qualidade de nosso trabalho é comprometida por causa do pouco tempo que temos". Em concordância ao fato de as propagandas não serem informativas, um colega afirma: "por falta de informação, de conhecimento de 500 que procuram atendimento, 200 vêm atrás de reclamações relativas a empréstimos consignados que não querem mais". Por fim, uma participante conclui: "a filosofia da instituição era espetacular. Hoje temos um sistema falho e lento".

Gaulejac (2007, p. 28) adverte que a sociedade se deixa contaminar pela ideologia gerencialista. "Nascida na esfera do privado, ela tende a se espalhar nos setores públicos e no mundo não comercial... Todos os registros da vida social são atingidos... O humano se torna um capital que convém tornar produtivo". Assim, o indivíduo apenas precisa tornar-se melhor para a empresa, seja ela pública ou privada, o que implica em tornar-se objeto de suas práticas, sustentando com o empréstimo de sua identidade os resultados e a competitividade organizacional, abrindo mão de seu lugar de sujeito, de fazer e ser inventor de sua trajetória. 
Os relatos do grupo reforçam a visão do autor. Os participantes queixam-se de suas perdas ao longo dos anos e das mudanças que foram sofrendo com a implementação dos novos modos de gestão. Um servidor menciona: "quando a gente entrou tinha ideais, hoje virou tudo burocracia, frustrações... há muitos conflitos entre as áreas e inimizade". Outro complementa: "antes éramos mais unidos, trabalhávamos bastante, mas éramos menos cobrados. A informatização também tornou tudo mais complicado e trouxe mais e mais trabalho".

Sobre o relacionamento com colegas, outro servidor ratifica: "os colegas são legais, mas o sistema acaba gerando uma grande desunião interna". Ao ouvir o colega, um participante acrescenta: "a nossa turma não é muito unida, não temos muitas conquistas enquanto classe. É mesmo cada um por si e cada um vai se defendendo sozinho como pode pra não cair doente em uma cama de hospital". E ainda: "quando tu chega num colega pra pedir ajuda, pedir alguma informação, vê que está todo mundo sozinho e perdido; cada um diz uma coisa". Outra servidora agrega mais uma informação importante: "e tem outro problema: o nosso trabalho ficou fragmentado. Tem a especialização do trabalho e a gente não tem a visão do todo".

Pode-se verificar que nesta ótica financeira todos são medidos pelo seu valor monetário em detrimento de uma reflexão sobre as formas de organização e sobre os problemas humanos. É como se a humanidade depusesse contra si mesma em benefício do capital. Nesse palco de contradições e incertezas, as razões econômicas prevalecem e derrubam todos os argumentos éticos e de preservação da saúde e do tecido social. "O gerencialismo liberal e a 'gestão de recursos humanos' produzem uma individualização das relações salariais, neutralizam as reivindicações coletivas e enfraquecem as solidariedades concretas" (Gaulejac, 2007, p. 50).

Na perspectiva de Paes de Paula (2012), a nova administração pública baseada no gerencialismo, na reprodução de técnicas administrativas do setor privado e na questão da eficiência, embora seja hegemônica, pode ser considerada um modelo de gestão em crise, tendo em vista seu caráter centralizador e a desarticulação existente entre os aspectos técnicos e políticos. Além disso, não se encaminha para a evolução e desenvolvimento da gestão pública, ou seja, não se buscam práticas administrativas apropriadas para a realidade do setor público, não se considera a inter-relação entre política e administração e não está voltada à democratização do Estado.

Nessa direção, um servidor relata:

o sistema de controle por tempo e produtividade que temos aqui em nada difere do setor privado; faz a gente trabalhar preocupado com o teu colega, se fulano está trabalhando ou se está parado. É o controle de um sobre o outro; todo mundo tem que ser ágil e agora também nos obrigam a periodicamente ser o responsável pelo controle do setor.

Pode-se verificar que os servidores encontram-se sem motivação para trabalhar, relatam ser penoso estar neste contexto. Pode-se inferir que há um apagamento do desejo de colocar seu fazer a serviço da instituição e, também, a serviço da vontade de dedicar-se à mesma. Nessa direção, Chanlat (2002) defende que a falta de motivação no serviço público está relacionada às profundas mudanças que ocorreram no setor nos últimos 20 anos, bem como ao descaso às especificidades deste tipo de trabalho.

Diante desse cenário de profundas transformações, um servidor do grupo diz que se encontra com as forças extenuadas, pois "o desafio é muito grande; somos colocados em cheque o tempo todo pela sociedade, atendemos quase 500 pessoas por dia. $\mathrm{O}$ atendimento tem que ser ágil, qualificado e correto e a população a ser atendida está crescendo a cada dia”.

Paes de Paula (2012) assevera que, no contexto da nova administração pública, a visão de profissionalização e formação de competências no serviço público ganhou traços gerencialistas, buscando a substituição da burocracia que visava assegurar a todos os cidadãos igualdade de 
serviços pela ótica gerencial de cunho meramente comercial. Entretanto, faz-se importante salientar que a burocracia não deixou de existir, apenas foi substituída pela burocracia flexível e, por isso, altamente perigosa, pois pode atender a interesses que rompem completamente com os fundamentos de uma suposta democracia e cujas características adaptam-se às necessidades contemporâneas de flexibilização organizacional. Um exemplo de flexibilização pode ser ilustrado através do que os servidores nomeiam "fila virtual":

há quantidade de atendimento e não resolução de problemas, então não tem mais a fila real que todo mundo enxergava. Parece que nosso trabalho diminuiu e que os problemas acabaram. Mas a fila é virtual, não diminuiu porque as pessoas têm que voltar para ter suas questões resolvidas.

Outro participante acrescenta: "acabou a fila aparentemente, mas na realidade, com todo retrabalho em função da pressa no atendimento, na verdade aumentou”. Essa constatação é reforçada por outro colega: "parece que a fila diminuiu, mas com esse sistema absurdo de agendamentos em um curto espaço de tempo, na verdade, a fila virtual aumentou". Conforme esse entrevistado, não sendo possível resolver as questões dos segurados em tão pouco tempo, mais demanda é gerada para os servidores e problemas para o segurado: "não há como resolver os problemas e a pessoa volta e volta. Na verdade, não resolveu nada e só está detonando com o servidor".

Neste sentido, outro participante expõe que as medidas propostas pelo governo não foram capazes de resolver o problema: "hoje existe a fila virtual e a fila real. Se criou uma série de medidas distantes da realidade. Não vemos políticas concretas que atendam a problemas reais". Outro acrescenta: "É uma fila virtual porque as pessoas agendam, mas ela é imensa porque com tudo isso, e com o pouco tempo para o atendimento, muitas coisas não são resolvidas, ficam pendentes".

Sobre as novas medidas, Pinto (2009) argumenta que se torna possível, ainda, que o processo de reforma administrativa desfile uma nova roupagem para métodos e técnicas antigas, mantidos por interesses políticos de uma elite dirigente e usando estratégias de manutenção e reprodução de práticas tradicionais, mas que não excluem a lógica gerencialista.

Nesta perspectiva, a penalização dos funcionários de escalão inferior, que atuam diretamente na prestação de serviços públicos, permanece e é perpetuada considerando que continuam sem perspectivas de carreira, enquanto o desenvolvimento da carreira dos burocratas pertencentes ao núcleo estratégico ganha mais valorização, o que revela o resgate do ideal tecnocrático. $\mathrm{O}$ fato de não existir uma carreira estruturada para os baixos escalões cria a tendência de que seja afetado o comprometimento dos funcionários com a profissão e com o interesse público (Paes de Paula, 2012).

Em relação a isso, não se pode deixar de apontar o relato de uma servidora que chega a uma conclusão pertinente ao seu trabalho e pede a pesquisadora que não deixe de considerar sua fala na pesquisa: "somos sobreviventes: estagiários, tecnologia, burocracia, metas, sobrecarga, falta de servidores, perda significativa de ganhos na aposentadoria. Somos os que ficamos e suportamos tudo isso". E, ainda: "ficamos parados no tempo, esquecidos, invisíveis, tendendo à mediocridade, ao descrédito e ao fracasso".

Filho e Navarro (2012) entendem que no universo capitalista contemporâneo somente quem consegue se ajustar à competição acirrada consegue reconhecimento e lugar garantido no que denominam ciranda gerencialista. Restam os excluídos, os que são colocados "na geladeira", ou ainda, aqueles que podem também ser chamados de sobreviventes, que persistem mesmo sentindo-se desvalorizados e inseguros, pois não sabem até quando poderão permanecer.

Sobre o trabalho do servidor público desta instituição, um participante aponta: 
nosso trabalho exige bastante. Precisamos saber de legislação e estar sempre atualizados, matemática, ter didática, diplomacia, conhecimentos de psicologia, para lidar com uma pessoa que não é alfabetizada, com um advogado, com alguém do meio rural, classes diversas

Uma colega acrescenta que, além de tudo, ainda precisam ter bastante paciência para lidar com o público diversificado a que atendem e, frequentemente, explicar as questões diversas vezes. A servidora também lembra que é necessário: "não demonstrar que tu está com pressa porque tem outros números esperando". Uma participante interrompe a colega e cita que, por vezes, os segurados imaginam que um amigo ou vizinho entende mais dos procedimentos do que o próprio servidor. Dessa forma, é necessário explicar várias vezes até a pessoa se convencer: "às vezes, eles colocam em dúvida o que tu está dizendo e acham que a vizinha sabe mais que a gente". Em concordância, outra colega menciona:

e tudo isso num curto espaço de tempo. Chega a ser desumano. É claro que a gente não pode enrolar, mas a pressão desta esteira de números que não param é enlouquecedora. Trabalhamos em cima de estatísticas e não de pessoas, mas são seres humanos que estão na nossa frente, cada um com a sua situação.

Revelando o amor pelo trabalho como uma forma de suportar tudo isso, uma participante, com a aquiescência do grupo expõe: "e esse trabalho é mesmo como um vício. Apesar de tudo, a gente ama o que faz, a função social que a gente cumpre, mesmo que leve na cabeça por causa disso". Em seguida, a servidora pontua o estresse no trabalho, as pressões sofridas e a grande responsabilidade que devem ter, conforme se observa: "é muito estressante o nosso trabalho. Há uma grande pressão do público e pressa no atendimento. Além disso, a responsabilidade é muito grande, pois lidamos com a vida das pessoas". Outro servidor salienta: "lidamos com o contraditório diariamente e diretamente. Isso nos faz pessoas diferentes. Nossa instituição é vista pelas pessoas como um lugar que nega tudo, mas não é verdade. Falta esclarecimento para as pessoas". Um colega corrobora: "nós mudamos a vida das pessoas. Temos mesmo em nossas mãos o poder de mudar a vida de uma pessoa. É isso que dá sentido ao nosso trabalho". Outro servidor aponta um paradoxo interessante: "em contradição a isso, o próximo que vamos atender, no sistema, é só um número, uma senha. Somos comandados por um número, como se o próximo a ser atendido fosse apenas mais um". Outro acrescenta: "e a fila anda depressa com inúmeros rostos passando rapidamente, mas para eles somos únicos; a gente não pode esquecer disso!”.

\section{Discussão}

Foi possível verificar que os servidores participantes da pesquisa encontram-se pouco mobilizados subjetivamente para o seu trabalho. Revelam ser penoso estar nesse contexto e sinalizam que há um apagamento do desejo de colocar seu fazer a serviço da instituição. Entendese que as razões para esse desinvestimento, as quais acarretam em grandes prejuízos para sua saúde mental, existem em função de diversos fatores, todos eles diretamente relacionados aos novos modos de gestão advindos da reforma gerencial do serviço público, cujos pilares encontram-se na lógica do mercado e cujo foco está nos resultados contábeis em detrimento dos resultados sociais.

No serviço público brasileiro, tal reforma gerou uma precarização crescente das relações de trabalho relacionada, principalmente, ao não preenchimento de vagas dos trabalhadores que deixam o serviço ou se aposentam, e à expansão crescente do processo de terceirização. Os contratos temporários, o tempo parcial e a quebra de vínculos, oriundos da gestão privada e 
amplamente disseminados na esfera pública, corroem as equipes de trabalho, geram insegurança, intensa sobrecarga e desgaste físico e mental, repercutindo sobre a saúde do servidor e, certamente, sobre a qualidade na prestação de serviços da administração pública.

No que se refere à instituição pesquisada, na maioria dos setores, havia número insuficiente de funcionários sendo que conforme relatos, na maior parte deles o contingente de estagiários chegava à metade do quadro efetivo. $\mathrm{O}$ fato desprestigia os servidores que passam por concursos, destruindo suas carreiras e desconsiderando a importância da formação, experiência e qualificação para o exercício do serviço público.

Percebeu-se, assim, que a lente do gerencialismo contemporâneo, que transforma tudo em números e cifras, leva a uma interpretação distorcida do mundo e solapa a busca pelo bem comum que constitui a base do serviço público. A ode à gestão privada invadiu o segmento, tendo como uma de suas mais danosas consequências a perda do sentido da ação pública.

Os participantes da pesquisa manifestaram, claramente, que a perda de referenciais balizadores do trabalho público acarretou desinteresse pela carreira pública como uma profissão geradora de prazer e realização, cujo sentido estava na causa pública, distinta dos interesses privados. A razão da escolha pela profissão reduziu-se apenas à suposta estabilidade que promete, mas que encontra-se em processo de desestabilização crescente.

Os estudos desenvolvidos a partir da presente pesquisa demonstraram que a mudança de concepção no interior do órgão público não ocorre de forma inofensiva, pois está abalando seus alicerces devido à negligência às suas especificidades em nome da suposta redução de custos. Constatou-se que, na prática, ao se transferir valores, diretrizes e procedimentos nascidos na esfera privada, o foco concentra-se na ampliação da produtividade e do retorno econômico, sendo implodidos os pilares que sustentavam esse trabalho público.

Os relatos dos servidores denunciam, ainda, a violência e o assédio organizacional aos quais se encontram expostos. Estes trabalhadores são assediados de diferentes formas, mas principalmente através da sobrecarga e da intensificação do trabalho associados à informatização e técnicas eficientes de controle do tempo e do espaço, bem como através do aumento da exigência de um desempenho ágil com predomínio da quantidade e produtividade em detrimento da prestação de um serviço de qualidade.

Além disso, o assédio organizacional se manifesta em outros aspectos, entre os quais se destaca a instabilidade da remuneração, que constitui fonte de grande desconforto considerando que a maior parte consiste em um salário variável que está atrelado à avaliação de desempenho e à produtividade, gerando muita insegurança. Acrescentam-se a isso, as perdas na aposentadoria; a ausência de um efetivo plano de carreira; a falta de incentivo e apoio à qualificação; a exposição às mudanças e decisões políticas constantes associadas à percepção de favoritismo e perseguição aos que se opõem a essa lógica, bem como a falta de acesso a oportunidades de crescimento. Como se não bastasse, o servidor sente-se exposto ao olhar de cobrança do público que o culpa pelo não atendimento de suas necessidades e, muitas vezes, desconsidera o seu papel social. Agrega-se a isso a falta de ações da instituição voltadas para a valorização do servidor e a evidente visão depreciativa da sociedade, que gera um profundo mal estar. Encontra-se, portanto, em um estado de solidão associado à erosão da convivência, da solidariedade, da cooperação e das coletividades em seu contexto laboral.

Nesta mesma direção, as qualidades do servidor público, no que se refere à dedicação, integridade, atenção igualitária, imparcialidade, justiça e garantia dos direitos do cidadão, que eram considerados de valor, passam a ser desconsiderados, deflagrando uma profunda crise de identidade e a queda no trabalho vazio aliado à perda das referências do que é ser servidor público, ou se este ainda tem lugar no cenário da reforma gerencial. A crise de identidade é 
agravada pela imitação do setor privado cuja prerrogativa está na valorização de uma nova imagem de sucesso que destrói as virtudes tradicionais do serviço público.

Faz-se importante salientar, também, que no âmbito da nova administração pública, o perfil gerencialista se alastrou, alcançando a visão de profissionalização e formação de competências no serviço público, sendo que a burocracia associada à igualdade na prestação de serviços foi substituída pela lógica gerencial de cunho unicamente comercial. Todavia, ainda existe uma burocracia extremamente incoerente e contraditória que parece preceder à iminência do caos, tendo em vista tratar-se de uma burocracia flexível com uma potência avassaladora, pois está a serviço de interesses que colocam em risco as conquistas sociais baseadas nos fundamentos da democracia, adaptando-se qual camaleão às demandas contemporâneas de flexibilização organizacional.

Tais situações encontram suas forças e se perpetuam a partir das pressões organizacionais, considerando que o ritmo frenético está atropelando as comunicações significativas e os relacionamentos, enquanto a competição acirrada está corroendo os laços afetivos. Além disso, o relato de sentirem-se sozinhos e desvalorizados, trabalhando além dos limites de suas forças, retrata um estado de imensa fragilidade e anulação psíquica, expostos ao desgaste mental e a consequentes abalos importantes em sua saúde física e psíquica. Cresce o risco cardiovascular, acirra-se o uso de medicações que, aliado ao sentimento de impotência, cansaço, insegurança e temor pelo futuro, amplia o risco de adoecimento, o que constatou-se através de um questionário aplicado nos participantes, também parte integrante da presente pesquisa.

Em contrapartida, quando se privilegiam relações de trabalho mais dignas, é oferecida ao trabalhador a possibilidade de sentir-se autenticamente engajado. No caso do serviço público, há o desejo expresso pelos participantes de promover o bem comum e a cidadania, o que é obstaculizado por metas impossíveis de serem alcançadas e que impedem a devida atenção ao segurado.

Isto reforça a importância da implementação de práticas profissionais construídas no recôndito do serviço público, alicerçadas no saber fazer do servidor, no respeito a sua engenhosidade com uma consideração efetiva do trabalho real, da inteligência prática e do zelo pelo servidor público, possibilitando a reapropriação do sentido de seu trabalho, que tem se perdido no vazio das prescrições da burocracia flexível e da lógica de resultados configurada nas senhas - como se não fossem pessoas - que precisam ser atendidas em um curto espaço de tempo, intensificando o trabalho e hipersolicitando o servidor, levando-o ao limite de suas forças e à exaustão.

\section{Conclusão}

Diante das constatações da presente pesquisa, pode-se considerar, a partir dos pressupostos da PDT, que há um trabalho político a ser feito no intuito de ressignificar o trabalho público, o que pode acontecer através da fala e da construção de um coletivo. Nessa ótica, considera-se que a emancipação torna-se possível quando, além do esforço individual, há o esforço coletivo das trocas entre os trabalhadores.

Constatou-se que há uma grande potência de mobilização coletiva para a ação no campo pesquisado e que, embora adormecida, manifestou-se na intensidade dos relatos advindos durante as discussões, embora haja ainda um longo caminho a ser trilhado para que um coletivo seja efetivamente construído. Assim, considera-se que esses espaços devam ser mantidos e ampliados a fim de que, juntos, os trabalhadores possam começar as mudanças necessárias em busca de mais saúde e emancipação, pois na ação coletiva podem ser sujeitos e autores de sua história. Em contrapartida, sozinhos, são meros objetos facilmente controlados e seduzidos pelo capital; 
além de frágeis, "quebrando-se" facilmente, e, quando os servidores encontram-se fragilizados, os cidadãos se enfraquecem. Quando os servidores calam-se sobre seus direitos, se emudece toda a sociedade e todo o sonho da democracia e igualdade de direitos.

Considera-se, por fim, que os resultados desta pesquisa dão visibilidade aos paradoxos da gestão e da reforma gerencial no serviço público, e abrem espaço para a reflexão sobre essas práticas e suas repercussões na saúde e subjetividade do trabalhador público, constituindo argumentos para o aprofundamento de estudos e pesquisas sobre as condições laborais nesse setor, buscando práticas de gestão que promovam um ambiente de trabalho mais saudável, onde prevaleçam relações simétricas geradoras de realização e emancipação, e não de servidão e submissão.

Finaliza-se ressaltando o desejo de que esta pesquisa possa impulsionar a ação transformadora de muitos trabalhadores públicos, e que futuras intervenções nesse campo constituam um instrumento de ampliação do som de muitas vozes que possam ecoar cada vez mais longe, fazendo valer a força de um coletivo que venha a mobilizar-se por relações de trabalho mais dignas e saudáveis, e pelo respeito ao importante papel social do servidor público na preservação da ética e do bem comum.

\section{Referências}

Brasil. (2012). Ministério da Saúde. Conselho Nacional de Saúde. Resolução nº 466/2012. Diretrizes e normas regulamentadoras de pesquisas envolvendo seres humanos. Brasília, DF.

Brasil. (2010) Portaria SRH no 1.261, de 5 de maio de 2010. Princípios, Diretrizes e Ações em Saúde Mental no âmbito da Administração Pública Federal. Brasília, DF: Ministério do Planejamento.

Bresser-Pereira, L. C. (2009). Construindo o Estado republicano: democracia e reforma da gestão pública. Rio de Janeiro, RJ: FGV.

Brulon, V., Ohayon, P. \& Rosenberg, G. (2012). A reforma gerencial brasileira em questão: contribuições para um projeto em construção. Revista do Serviço Público, 63(3), 265-284.

Carneiro, S. A. C. (2006). Saúde do trabalhador público: questão para a gestão de pessoas. A experiência na Prefeitura de São Paulo. Revista do Serviço Público, 57(1), 23-49.

Carneiro, S. A. M. (2011). Saúde do servidor: uma questão para a gestão de pessoas. Anais do IV Congresso CONSAD de Gestão Pública. Brasília, DF.

Chanlat, J. F. (2002). O gerencialismo e a ética do bem comum: a questão da motivação para o trabalho nos serviços públicos. Anais do VII Congreso Internacional del CLAD sobre la Reforma del Estado y de la Administración Pública. Lisboa, Portugal.

Dejours, C. (1992). A loucura do trabalho: estudo de psicopatologia do trabalho. São Paulo, SP: Oboré/Cortez.

Brasil. (2011). A metodologia em Psicodinâmica do Trabalho. In LANCMAN, S.; SZNELWAR, L. I. (orgs.). Christophe Dejours: Da psicopatologia à psicodinâmica do trabalho. Rio de Janeiro, RJ: Fiocruz; Brasília, DF: Paralelo 15.

Ferreira M. C., Alves, L, \& Tostes, N. (2009). Gestão de Qualidade de Vida no Trabalho (QVT) no serviço público federal: o descompasso entre problemas e práticas gerenciais. Psicologia: Teoria e Pesquisa, 25(3), 319-327.

Ferreira M. C. et al. (2011). Dominação e resistência no trabalho: concepção e modos de expressão. In M. C. Ferreira, et al. (Orgs), Dominação e resistência no contexto trabalho-saúde. São Paulo, SP: Universidade Presbiteriana Mackenzie.

Filho, L. G. C., \& Navarro, V. L. (2012). Organização do trabalho em saúde em um contexto de precarização e do avanço da ideologia gerencialista. Revista Pegada, 13(2), 67-82.

Gaulejac, V. (2007). Gestão como doença social: ideologia, poder gerencialista e fragmentação social. Aparecida, SP: Ideias e Letras. Merlo, A. R., \& Mendes, A. M. B. (2009). Perspectivas do uso da psicodinâmica do trabalho no Brasil: teoria, pesquisa e ação. Cadernos de Psicologia Social e do Trabalho, 12(2), 141-156.

Osborne, D., \& Gaebler, T. (1994). Reinventando o governo. Brasília, DF: MH Comunicação.

Paes de Paula, A. P. (2012). Por uma nova gestão pública. Rio de Janeiro, RJ: FGV. 
Osborne, D., \& Gaebler, T. (2005). Administração pública brasileira: entre o gerencialismo e a gestão social. RAE: Revista de Administração de Empresas, 45 (1), 36-49

Pinto, I. C. M. (2009). Reforma gerencialista e mudança na gestão do sistema nacional de vigilância sanitária. In E. A. Costa, (Org.). Vigilância Sanitária: temas para debate. Recuperado de www.scielo.br

Siqueira, M. V. S., \& Mendes, A. M. B. (2009). Gestão de pessoas no setor público e a reprodução do discurso do setor privado. Revista do Serviço Público, 60 (3), 241-250.

Secchi, L. (2009). Modelos organizacionais e reformas da administração pública. RAP, 43(2), 347-362.

Seligman-Silva, E. (2011). Trabalho e desgaste mental: o direito de ser dono de si mesmo. São Paulo, SP: Cortez.

Supiot, A. (1995). A crise do espírito de serviço público. Adverso: Revista da Associação de Docentes da UFRGS, 5(7), $16-25$.

Vaistman, J. (2001). Gerencialismo, cultura e expectativas entre servidores públicos de saúde . RAP: Revista de Administração Pública, 35(1), 29-47.

Endereço para correspondência

elisetetraesel@unifra.br
Recebido em: 22/04/2014

Revisado em: 11/01/2015

Aprovado em: 23/02/2015 